\title{
Preparing for an Influenza Pandemic: Policy Implications for Rural Latino Populations
}

\author{
Eulalia Witrago, MPH \\ Miguel A. Perez, PhD
}

\begin{abstract}
The purpose of this study was to assess influenza preparedness levels among Spanish-speaking adults ages 18 and older in two rural communities in Central California. Data were collected from 209 participants using the 21-item Emergency Preparedness Measurement Scale, an instrument designed and validated for this study. Results suggest that adult Spanish-speaking Latinos are not prepared for a pandemic influenza regardless of their gender, age, number of years living in the United States, education, or income level. Furthermore, study participants cited lack of insurance, limited knowledge about needed emergency supplies, and preference for fresh foods as reasons for lacking emergency supplies at home.
\end{abstract}

Key words: Emergency preparedness, Latinos, rural areas, influenza.

$\mathrm{T}$ he research literature underscores emergency preparedness, including the threat of an influenza pandemic, as an invaluable tool to minimize preventable morbidity and mortality ${ }^{1}$ when the unexpected occurs. Current recommendations for emergency preparedness encompass (1) building an emergency kit that includes items necessary to survive for at least three days (see Box 1); (2) making a plan for what to do during and immediately following an emergency, including selecting two meeting locations where the family would be able to reunite in the event that the home is inaccessible; and (3) being informed regarding the potential for an emergency. ${ }^{2-5}$ Being informed at all times regarding what could happen and how to help in the event of an emergency is also an important part of emergency preparedness. Most importantly, it is recommended that individuals share the information and the preparedness steps they have learned with others. The recommendations outlined in this paragraph are based on the assumption that in large-scale natural disasters emergency medical services may not reach large population segments for up to 72 hours.

While people tend to think of emergencies in terms of natural disasters, emergency preparedness should include health emergencies such as an influenza pandemic. This fact is recognized by the U.S. Department of Health and Human Services, which maintains a website (www.flu.gov) designed to provide information on influenza, dis-

EULALIA WITRAGO is affiliated with the Fresno County Department of Public Health. MIGUEL A. PEREZ is the Chair of the Department of Public Health at California State University, Fresno in Public Health. He can be reached there at 2345 E. San Ramon Ave., MS 30, Fresno, CA 93740; (559) 278-4014; mperez@csufresno.edu. 


\section{Box 1.}

\section{RECOMMENDED ITEMS TO INCLUDE IN A BASIC EMERGENCY SUPPLY KIT}

- Water, one gallon of water per person per day for at least three days, for drinking and sanitation

- Food, at least a three-day supply of non-perishable food

- Battery-powered or hand crank radio and a NOAA Weather Radio with tone alert and extra batteries for both

- Flashlight and extra batteries

- First aid kit

- Whistle to signal for help

- Dust mask, to help filter contaminated air and plastic sheeting and duct tape to shelter-in-place

- Moist towelettes, garbage bags and plastic ties for personal sanitation

- Wrench or pliers to turn off utilities

- Can opener for food (if kit contains canned food)

- Local maps

- Cell phone with chargers

Additional Items to Consider Adding to an Emergency Supply Kit:

- Prescription medications and glasses

- Infant formula and diapers

- Pet food and extra water for your pet

- Important family documents such as copies of insurance policies, identification and bank account records in a waterproof, portable container

- Cash or traveler's checks and change

- Emergency reference material such as a first aid book or information from www .ready.gov

- Sleeping bag or warm blanket for each person. Consider additional bedding if you live in a cold-weather climate.

- Complete change of clothing including a long sleeved shirt, long pants and sturdy shoes. Consider additional clothing if you live in a cold-weather climate.

- Household chlorine bleach and medicine dropper-when diluted nine parts water to one part bleach, bleach can be used as a disinfectant. Or in an emergency, you can use it to treat water by using 16 drops of regular household liquid bleach per gallon of water. Do not use scented, color safe or bleaches with added cleaners.

- Fire extinguisher

- Matches in a waterproof container

- Feminine supplies and personal hygiene items

- Mess kits, paper cups, plates and plastic utensils, paper towels

- Paper and pencil

- Books, games, puzzles or other activities for children 
seminate educational materials, and provide up-to-date information for individuals, communities, businesses, schools, and health care providers. In the section designated for individual planning, the site provides an overview on pandemic influenza, a family guide, checklists, and information sheets. This section also offers information on the possibility of not being able to work during a pandemic, recommendations on the need to stay at home during an epidemic, and the warning that schools may be closed during a pandemic. The website provides information in English, Spanish, Chinese, and Vietnamese.

The California Department of Public Health (CDPH) maintains a website (http:// bepreparedcalifornia.ca.gov/epo/) designed to educate Californians about the need to be prepared for all types of emergencies. Through its website, the CDPH educates the public on the differences between seasonal and pandemic influenza, provides information on how individuals can prepare for a pandemic influenza, publishes the California pandemic influenza plan, answers frequently asked questions about influenza, and offers sound advice on how to care for individuals at home during a pandemic influenza. Even though this web site offers abundant information, it offers only limited information in Spanish and for more refers visitors to the official U.S. government website discussed above. The site provides a useful definition for public health emergencies that would include an influenza pandemic.

The Fresno County Department of Public Health (FCDPH) maintains its own website (http://www.fcdph.org) containing educational tools such as brochures, checklists, and fact sheets. Available information includes pages describing the differences between seasonal influenza, avian influenza in birds, avian influenza in humans, and pandemic influenza. Additionally, fact sheets and checklists regarding preparedness steps are also available on this site.

Seasonal influenza. There are three types of viruses, known as Influenza A, B, and C, which cause the flu. Influenza types A and B are responsible for the respiratory disease that occurs every winter and type $\mathrm{C}$ usually causes mild disease, sometimes causing no symptoms. Every year more than 200,000 people are hospitalized in the United States due to seasonal influenza complications and about 36,000 people die as a result of influenza infection. ${ }^{6}$ People at high risk of seasonal influenza complications are those aged 65 and older, very young children, and individuals of any age with certain chronic medical conditions such as asthma, diabetes, or heart disease. ${ }^{7}$ Annual influenza outbreaks are due to minor changes in the surface proteins of the virus, which enable the viruses to infect humans even when prior immunity or vaccination has been acquired. ${ }^{8}$ While most Americans consider the annual flu vaccination as adequate preparedness, the 2005 worldwide avian flu and the $2009 \mathrm{H} 1 \mathrm{~N} 1$ pandemic influenza have demonstrated the need also to be prepared to deal with influenza pandemics.

Influenza pandemics. A pandemic is defined as an epidemic that becomes widespread and affects a whole region, continent, or the world. ${ }^{9-10}$ An influenza pandemic is an outbreak of disease that occurs when a new influenza A virus-the only type that can cause pandemics in humans-emerges and human populations have little or no immunity, ${ }^{8}$ resulting in an unusually high number of illnesses and deaths for approximately two to three years. ${ }^{11-12}$

Influenza viruses are spread mainly from person to person through coughing or 
sneezing with a transmission period lasting from one day before symptoms develop and up to five days after becoming sick. ${ }^{6}$ Another route by which individuals can become infected is by touching something with the influenza virus and then touching his or her mouth or nose. ${ }^{13}$

Influenza pandemics are rare events, yet three occurred in the 20th century: Spanish Influenza of 1918, Asian Influenza of 1957, and the Hong Kong Influenza of 1968. The Spanish Influenza is considered one of the deadliest disease events in human history, killing an estimated 40-50 million people worldwide ${ }^{8}$ and a half-million people in the United States. ${ }^{14}$ The Asian pandemic caused an estimated two million deaths worldwide ${ }^{8}$ and 70,000 deaths in the United States. ${ }^{15}$ The Hong Kong pandemic caused an estimated one million deaths worldwide including 34,000 deaths in the United States. ${ }^{8,10,15-16}$

It has been 40 years since the last pandemic influenza and some scientists believe that it is only a matter of time before the next one occurs. ${ }^{12,17-18}$ The threat presented by the H1N1 virus in 2009 made this projection more real because of the high mortality rate in infected humans. ${ }^{19-20}$ According to one set of estimates, the next pandemic influenza in the United States could have an attack rate of $30 \%{ }^{21}$ with an estimated 90 million cases nationwide. Especially worrisome is the fact that only $50 \%$ of those who will be affected are expected to seek medical care, which could result in between 209,000 and 1,903,000 deaths. ${ }^{21}$ Considering such alarmingly high morbidity and mortality rates, public health professionals must understand and be ready to implement national, state, and local preparedness plans, especially among under-represented populations.

Influenza preparedness. The national Health and Human Services Pandemic Influenza Plan, published in November 2005, calls for state and local health departments to develop and disseminate educational messages to the public, the medical community, and other stakeholders about influenza preparedness. ${ }^{21}$ Supplement 10 in the national plan is dedicated to the importance of public health communications and provides recommendations on risk communication principles that are essential to the planning and implementation of communication activities before, during, and after an influenza pandemic. Collaborative planning is recommended at the local, regional, state, and national levels. The provision of timely and accurate information and messages regarding what is known and what is not known is also recommended.

Supplement 10 also focuses on additional demands that a pandemic influenza may pose for public officials, including the need to ensure that groups with special needs receive information in a way that meets their needs. For instance, non-English speaking individuals will need to receive information in their own language.

The California Department of Public Health has developed an annex to the state's existing Public Health Emergency Response Plan and Procedures to include the Pandemic Influenza Preparedness and Response Plan. ${ }^{11,22}$ The purpose of the plan is to outline the roles and strategies of CDPH in coordinating public health preparedness, response, and recovery activities for pandemic influenza with local health departments, the health care community, the federal government, and other key partners. Chapter 10 in the state's plan addresses risk communication and calls for messages to be developed at a level that can be understood by all members of the public including those who do not speak English. This section underscores the need to implement effective risk communication during a pandemic influenza to guide the public, news media, health care 
providers, and other agencies in responding to the outbreak, adhere to public health measures, and to understand state and local response efforts.

The Fresno County Department of Public Health (FCDPH), formerly the Fresno County Department of Community Health, is a local governmental entity responsible for pandemic influenza preparedness. As part of this responsibility, FCDPH has developed a Pandemic Influenza Plan (section VI) under the Public Health Emergency Preparedness Plan and Response. ${ }^{23-24}$ The FCDPH's plan highlights the importance to provide risk communication messages to the public regarding self care and health directives. This plan also presents recommendations regarding the best methods of communication (e.g., media, community partners) to reach at-risk and hard-to-reach populations such as Spanish-speaking individuals.

The FCDPH plan was established utilizing the 1-2-3-4-5-6 classification of Pandemic Phases of the World Health Organization. Each section covers the following seven components as they apply to each of the pandemic phases: command and control, surveillance, isolation and quarantine, social distancing, laboratory capacity, FCDPH and community services, and vaccine and antiviral medications. According to the FCDPH the next pandemic influenza in Fresno County would cause approximately 300,000 cases, and of those cases, $50 \%$ would seek medical care with an excess mortality anticipated of between 690 to 6,330 deaths. These estimates were completed using data from the three pandemics of the 20th century, based on a population of one million, and using the same attack rate of $30 \%$ as projected by the U.S. Department of Health and Human Services.

At-risk populations. The research literature has identified severe poverty, language barriers, low insurance rates, race/ethnicity, and religious affiliation among the factors that could worsen the effects of an influenza pandemic among U.S. population groups. Given the special needs and barriers some of these populations might face during an influenza pandemic, the literature suggests that public health professionals pay special attention to them in preparing for the next pandemic. ${ }^{25}$

Latino population. It is estimated that Latinos account for $49 \%$ of the Fresno County population, almost half (45\%) were born in Mexico, and almost a third (32\%) speak only Spanish. ${ }^{26-28}$ Given the large proportion of Hispanics in Fresno County, the purpose of this study was to identify the level of influenza preparedness among Spanish-speaking adults ages 18 and older in two rural communities.

\section{Methods}

Instrument development. Data for this study were collected using the Emergency Preparedness Measurement Scale (EPMS), a 21-item instrument designed to measure influenza preparedness among Latinos in rural communities. A review of the literature did not identify a single valid instrument designed to measure the variables of interest in this study, therefore, the EPMS was developed. A pool of questions was created based on an extensive literature review, which included emergency preparedness instruments. ${ }^{29-34}$ All of the questionnaires had similar questions in areas related to personal and household preparedness, steps taken towards preparedness including storing of food, water, a flashlight and battery operated radio, medical supplies, development of 
a plan with information on where to go and who to call, effective ways of obtaining information, and demographic information including ZIP code, gender, education level. The original pool of 87 questions was reduced to 21 based on recommendations from a panel of experts who reviewed the instrument for completeness and recommended removal of duplicate items.

Instrument translations. The EPMS was developed in English and subsequently translated to Spanish. The translation was performed by a baccalaureate degree-holding bilingual/bicultural person who has eight years of experience working in the public health field as well as extensive experience working with Latino populations in the Central California area.

The Spanish version of the EPMS was back-translated to English by a different baccalaureate degree-holding bilingual/bicultural individual with many years of experience in the field. In addition to the formal translation and back-translation, the instrument was carefully reviewed by the investigators, who are both bilingual/bicultural.

The instrument translation and back-translation process did not result in major changes to the EPMS (there was a 22-word difference, which did not affect the content or the focus of inquiry). Examples of the discrepancies include the use of the words conducted versus carried out, hope versus wish, completed versus finishes, outbreak of disease versus sprout of disease, and medicines versus medications. Both the translator and back-translator agreed that the reading level was appropriate for the target population.

Pilot study. Thirty individuals sharing many of the demographic characteristics of the target population participated in a pilot test of the instrument. The researcher provided a brief introduction of the study, requested the individuals' participation, and obtained informed consent to participate. Modifications were made to the instrument based on comments from the pilot study participants.

Data collection. Data for this study were collected from 209 individuals receiving educational, parenting, or health informational services from two rural school districts in Fresno County, California. Representatives from each of the data collection sites determined the best days and times for data collection, thereby, maximizing response rates.

The Principal Investigator for this study approached potential study participants at each data collection site and provided an oral and written introduction to the study before individuals were asked to participate. Once the individual agreed to proceed, a written consent form was provided. Because the study population was mostly Spanishspeaking individuals, the consent form was translated into Spanish and back-translated into English following the format described for the instrument development.

As an incentive to participate in the study, participants were entered into a raffle for a first aid emergency kit valued at $\$ 25$. A raffle ticket was provided to each participant at the time they signed the consent form. Once the participants read and signed the consent form a copy of the EPMS was provided to each of them. The raffle was performed upon completion of data collection at each of the data collection sites; no contact information was retained by the investigators.

Data analysis. Data were analyzed using the Statistical Package for the Social Sciences (SPSS) data analysis software. Data were transformed to create variables that would allow the research team to answer the research questions. For instance, in order to determine if participants had an emergency kit, questions asking if they had a gallon 
of water per family member for at least three days, whether or not they had food that would not spoil and would supply nourishment to each family member for at least three days, and whether or not they had enough medications or medical supplies to address the needs of each family member for at least three days were aggregated into a single variable. If an individual responded to having all three of these, then they were determined to have an emergency kit at home. The study did not investigate whether or not participants stockpiled bedding, clothing, or tools as part of their emergency kit.

\section{Results}

Table 1 presents the demographic characteristics of the sample. The majority of the participants were women, between the ages of 35-54, born in Mexico, had resided in the United States for 10 or more years, had less than a high school degree, and had a household income level of less than $\$ 24,000$.

Results summarized in Table 2 show that Latinos in the two rural communities studied were not prepared for a flu emergency. Statistical analysis did not find differences based on language, gender, age, or length of stay in the U.S. This finding suggests that Latinos residing in rural communities, regardless of their level of acculturation, are not

\section{Table 1.}

DEMOGRAPHIC CHARACTERISTICS

\begin{tabular}{lrr} 
Demographics & n & $\%$ \\
\hline Gender & & \\
$\quad$ Females & 148 & 71 \\
Males & 59 & 28 \\
Unknown & 2 & 1 \\
Age & & 35 \\
18-34 & 74 & 57 \\
$25-54$ & 119 & 5 \\
$55-64$ & 11 & 1 \\
65 or older & 2 & 1 \\
Unknown & 3 & 8 \\
Country of birth & & 89 \\
USA & 16 & 3 \\
Mexico & 185 & 1 \\
Other & 6 & 3 \\
Unknown & 2 & 12 \\
Years residing in USA & & 19 \\
$0-1$ & 6 & 66 \\
$1-5$ & 25 & (Continued on p. 65) \\
$5-10$ & 40 & \\
10 or more & 138 & \\
& & \\
& &
\end{tabular}




\section{Table 1. (continued)}

\begin{tabular}{lrc}
\hline \hline Demographics & $\mathbf{n}$ & \% \\
\hline Educational Level & & \\
$\quad$ Some elementary & 38 & 18 \\
Completed elementary & 48 & 23 \\
Some high school & 26 & 12 \\
Completed high school & 42 & 20 \\
Some college or university & 38 & 18 \\
Completed college or university & 15 & 7 \\
Unknown & 2 & 1 \\
Income & & 58 \\
Less than $\$ 24,000$ & 121 & 22 \\
24,000-\$30,000 & 45 & 15 \\
More than $\$ 30,000$ & 31 & 6 \\
Unknown & 12 & \\
\hline
\end{tabular}

prepared to deal with a flu pandemic and that this lack of preparation places them at a high risk for unnecessary morbidity and mortality in case of an influenza pandemic.

Findings from this study suggest that the majority of the participants would first contact their doctor in case of an influenza pandemic (see Table 3). The county health department was listed as the second source of information and the police department was listed as the third most likely place for participants to turn for information during an influenza pandemic. This last finding strongly suggests a need for public health professionals to work with traditional emergency services providers in developing and implementing influenza pandemic prevention strategies.

When asked about the qualifications they would like to see in a person implementing prevention messages most participants identified a medical provider as a first choice (Table 4). Health educators were listed second as a trusted source of information by study participants. Participants most frequently identified television, radio, or newspapers as their preferred source of information about a pandemic (Table 5).

\section{Table 2.}

STATISTICAL DATA SUMMARY

\begin{tabular}{lccc}
\hline \hline Variable & Number & $\mathbf{c}^{2}$ & p value \\
\hline Gender & 207 & 2.87 & .136 \\
Years in the U.S. & 209 & 3.11 & .070 \\
Age & 206 & .33 & .737 \\
Educational level & 207 & .32 & .696 \\
Income level & 197 & .0017 & .992 \\
\hline
\end{tabular}




\section{Table 3.}

\section{INITIAL CONTACT OF PARTICIPANTS}

\begin{tabular}{lrc}
\hline \hline Contact & n & \% \\
\hline Doctor & 82 & 39 \\
Health department & 72 & 34 \\
Police/911 & 31 & 15 \\
Hospital & 15 & 7 \\
Family/friend & 5 & 2 \\
Other & 1 & 1 \\
Unknown & 2 & 1 \\
Total & 209 & 100 \\
\hline
\end{tabular}

Participants were asked about the best days and times to conduct educational campaigns that would have minimal impact in their daily routines. Study participants indicated that 5:00 p.m. to 9:00 p.m. on weekdays were the best days to attend a presentation on pandemic influenza.

Tables 6-8 provide insight into the lack of influenza pandemic preparedness by study participants. Forty-two percent of the participants indicated they did not know they needed to have water stored in case of an emergency, $43 \%$ suggested they did not store food as part of their emergency supplies because they either did not like canned food or preferred only fresh food, and 25\% indicated lack of insurance as the reason for the lack of stored medications.

\section{Discussion}

Previous studies have identified guidelines for the development of culturally relevant emergency preparedness messages and education strategies for Latino populations. ${ }^{34-35}$ Results from this study support the urgent need to develop influenza preparedness

\section{Table 4.}

\section{PREFERRED PRESENTER}

\begin{tabular}{lrr}
\hline \hline Presenter & $\mathbf{n}$ & \% \\
\hline Doctor/nurse & 94 & 45 \\
Health educator & 85 & 41 \\
Emergency services personnel & 28 & 13 \\
Unknown & 2 & 1 \\
Total & 209 & 100 \\
\hline
\end{tabular}




\section{Table 5.}

\section{PREFERRED SOURCE FOR OBTAINING INFORMATION OF PARTICIPANTS}

\begin{tabular}{lrr}
\hline \hline Source & $\mathbf{n}$ & $\%$ \\
\hline Television, radio or newspaper & 73 & 35 \\
Doctor & 57 & 27 \\
Health department & 51 & 24 \\
Hospital & 10 & 5 \\
Internet & 9 & 4 \\
Other & 9 & 4 \\
Total & 209 & \\
\hline
\end{tabular}

materials for Spanish-speaking rural populations. To address the needs identified in this study, the authors recommend that a multi-faceted community outreach campaign be developed, pilot-tested, implemented, and evaluated to measure its effectiveness in bring influenza preparedness information to Spanish-speaking Latinos in rural central California.

Given the lack of resources devoted to this topic, it is recommended that the local health department be identified as the lead agency for this campaign. Additionally, it is suggested that the lead agency should engage community partners in forming a grassroots coalition dedicated to the development of print materials as well as mass media messages dealing with influenza preparedness.

An essential element of these efforts should be the engagement of Spanish media leaders to ensure steady airing of Spanish-language influenza preparedness public service announcements (PSAs). Local community leaders and respected civil authorities should be recruited to deliver prevention messages that would focus on the need to be vaccinated on a yearly basis.

\section{Table 6.}

\section{REASONS WHY PARTICIPANTS DO NOT STORE WATER}

\begin{tabular}{lrc}
\hline \hline Reason & $\mathbf{n}$ & $\%$ \\
\hline Only use big or small bottles & 7 & 18 \\
Did not know it is needed & 16 & 42 \\
Use city water & 6 & 16 \\
Procrastinate & 4 & 11 \\
Do not think it is necessary & 5 & 13 \\
Total & 38 & 100 \\
\hline
\end{tabular}




\section{Table 7.}

\section{REASONS WHY PARTICIPANTS DO NOT STORE FOOD}

\begin{tabular}{lcc}
\hline \hline Reason & $\mathbf{n}$ & $\%$ \\
\hline Forget or procrastinate & 5 & 26 \\
Never thought about a disaster & 2 & 11 \\
No money & 3 & 16 \\
Do not like canned food & 6 & 32 \\
Only eat freshly made food & 2 & 11 \\
Family eats all food available & 1 & 5 \\
Total & 19 & 100 \\
\hline
\end{tabular}

Rural communities should work in the development of local speaker bureaus recruited from the local public health community. Professional and lay health educators should be trained in influenza prevention messages, emergency kit development, what to include in an emergency plan, how to stay informed, and what to do and how to care of family members if anyone gets sick.

In addition to the speaker bureau, the lead agency should recruit and train community individuals to become Promotoras de Salud (health promoters). The Promotoras de Salud model has been very successful in educating patients about diabetes treatment and lead poisoning prevention, and in Fresno County, educating women on chronic disease reduction and the importance of healthy eating and staying physically active.

None of these recommendations will be successful unless they are widely announced and implemented. Initial community locations where educational presentations should

\section{Table 8.}

\section{REASONS WHY PARTICIPANTS DO NOT STORE MEDICINE}

\begin{tabular}{lcr}
\hline \hline Reason & n & $\%$ \\
\hline Do not know which ones & 3 & 15 \\
Medicine expires & 1 & 5 \\
Need other medicines & 2 & 10 \\
Not thought about it & 3 & 15 \\
No money or insurance & 5 & 25 \\
Family does not get sick often & 2 & 10 \\
Not have enough & 3 & 15 \\
Procrastinate & 1 & 5 \\
Total & 20 & 100 \\
\hline
\end{tabular}


be provided include adult education centers including English as a Second Language classes and GED preparation programs. Classes should be provided during the evening hours on a Monday-to-Friday training schedule. A few sessions should also be offered on Saturdays for those participants who might not be available during the week.

An additional component of this community outreach approach is the dissemination of the educational message and print materials via doctors' offices. Although the majority of respondents in the current study indicated medical providers would be their first source of information during an influenza pandemic, the reality is that these professionals are the least likely to provide prevention messages. Therefore, printed materials that take into account the health literacy level of the target populations should also be provided at these medical offices to be utilized in their waiting areas. Finally, these printed materials should be developed specifically for the target populations and not be simple translations of existing materials developed for general audiences.

Economic reductions have forced many public health entities to decrease the amount of printed materials and rely mostly on electronic media to disseminate information. Findings from this study suggest that less than $10 \%$ of the sample population would turn to the Internet to obtain this information making this medium an ineffective method for reaching the population during an influenza pandemic.

Spanish-speaking populations represent a significant population segment in central California communities. Geographic isolation, language barriers, and limited access to health services contribute to an increase risk for devastating outcomes during an influenza pandemic. Results from this study reveal important steps public health professionals can take to ameliorate the impact of an influenza pandemic.

\section{Acknowledgments}

The authors wish to express their appreciation to Dr. Helda Pinzon-Perez, Dr. Suzanne Kotkin-Jaszi, and Mr. Steve Ramirez for their contributions to earlier versions of this manuscript.

\section{Notes}

1. American Red Cross. 2007. Get prepared. Retrieved January 6, 2008, from http:// www.redcross.org/services/prepared/0,1082,0_77_00.html.

2. American Red Cross. (n.d.) Pandemic flu-planning ahead. Retrieved November 28, 2007, from http://www.redcross.org/news/ds/panflu/planahead.html.

3. FEMA. (n.d.) Basic disaster supplies. Retrived October 22, 2010, from http://www .fema.gov/plan/prepare/basickit.shtm.

4. Ready America. 2009. Get a kit. Retrieved October 22, 2010, from http://www.ready .gov/america/getakit/.

5. U.S. Department of Health and Human Services. 2010. Individuals and family planning. Retrieved October 22, 2010, from http://www.pandemicflu.gov/plan/individuals/index .html.

6. Centers for Disease Control and Prevention. 2010. Influenza (flu) what everyone should know about flu and the flu vaccine. Retrieved October 22, 2010, from http:// www.cdc.gov/flu/keyfacts.htm. 
7. Centers for Disease Control and Prevention. 2010. Influenza (flu) the disease. Retrieved October 22, 2010, from http://www.cdc.gov/flu/about/disease.htm.

8. World Health Organization. 2006. Ten things you need to know about pandemic influenza. Retrieved February 8, 2006, from http://www.who.int/csr/disease/influenza /pandemic10things/en/print.htms.

9. Chan WF, Wong TKS. Preparing for pandemic influenza: revisit the basics. Journal of Clinical Nursing. 2007;16:1858-64.

10. Inglesby TV, Nuzzo JB, O’Toole T, et al. Disease mitigation measures in the control of pandemic influenza. Biosecurity and Bioterrorism: Bioterrorism Strategy, Practice, and Science. 2006;4:1-10.

11. California Department of Health Services. 2010. Pandemic influenza preparedness and response plan. Retrieved October 22, 2010, from http://bepreparedcalifornia.ca .gov/EPO/BeInformed/Flu/PandemicFlu/PandemicFlu.htm.

12. Canadian Centre for Occupational Health and Safety. 2006. Pandemic influenza. Retrieved September 14, 2006, from http://www.ccohs.ca/oshanswers/diseases/pandemic _flu.html?print.

13. Centers for Disease Control and Prevention. 2010. Influenza (flu) the influenza (flu) viruses. Retrieved October 22, 2010, from http://www.cdc.gov/flu/about/fluviruses .htm.

14. Fauci AS. Emerging and reemerging infectious diseases: the perpetual challenge. Academic Medicine. 2005;80:1079-89.

15. Bartlett JG, Hayden FG. Influenza A (H5N1): will it be the next pandemic influenza? Annals of Internal Medicine. 2005;143:460-2.

16. Gensherimer KF, Meltzer MI, Postema AS, et al. Influenza pandemic preparedness. Emerging Infectious Diseases. 2003;9. Retrieved October 20, 2006, from http://www .cdc.gov/ncidod/EID/vol9no12/03-0289.htm.

17. Osterholm MT. Preparing for the next pandemic. New England Journal of Medicine. 2005;352(18):1839-42.

18. Patterson MM. The coming influenza pandemic: lessons from the past for the future. The Journal of the American Osteopathic Association. 2005;105:498-500.

19. Webster RG, Govorkova EA. H5N1 influenza-continuing evolution and spread. New England Journal of Medicine. 2006;355:2174-7.

20. World Health Organization. 2007. Epidemic and pandemic alert and response. Retrieved October 14, 2007, from http://www.who.int/csr/disease/avian_influenza /country/cases_table_2007_10_12/en/.

21. U.S. Department of Health and Human Services. 2005. Health and human services pandemic influenza plan. Retrieved November 14, 2007, from http://www.hhs.gov /pandemicflu/plan/pdf/HHSPandemicInfluenzaPlan.pdf.

22. California Department of Public Health. (n.d.). Pandemic flu. Retrieved October 22, 2010, from http://bepreparedcalifornia.ca.gov/EPO/BeInformed/Flu/PandemicFlu /PandemicFlu.htm.

23. Fresno County Department of Public Health. 2010. Public health emergency preparedness and response programs. Retrieved October 22, 2010, from http://www.co.fresno .ca.us/DivisionPage.aspx?id=35427.

24. Fresno County Department of Community Health. Pandemic influenza response plan, Section VI. Fresno, CA: Public Health Emergency Preparedness and Response Plan, 2007.

25. Uscher-Pines L, Duggan PS, Garoon JP, et al. Planning for an influenza pandemic: social justice and disadvantage groups. Hastings Center Report. 2007 July-Aug;32-9. 
26. U.S. Census Bureau. 2009. Fresno County quickfacts. Available at: http://quickfacts .census.gov/qfd/states/06/06019.html

27. U.S. Census Bureau. 2008. 2006-2008 American Community Survey 3-year estimates. Available at: http://factfinder.census.gov/servlet/ACSSAFFFacts?_event=\&geo _id=05000US06019\&_geoContext $=01000 U S \mid 04000$ US06|05000US06019\&_street $=\& \_$county $=$fresno\&_cityTown $=$fresno\&_state $=04000$ US06\&_zip $=\& \_l a n g=e n \& \_s s e$ $=$ on \&ActiveGeoDiv $=\& \_u s e E V=\& p c t x t=f p h \& p g s l=050 \& \_s u b m e n u I d=$ factsheet_1 $\& d s \_n a m e=n u l l \& \_c i \_n b r=$ null $\& q r \_n a m e=n u l l \& r e g=$ null $\% 3$ Anull $\& \_k e y w o r d=\&$ _industry=.

28. U.S. Census Bureau. 2008. 2006-2008 American Community Survey 3-year estimates. Available at: http://factfinder.census.gov/servlet/ADPTable?_bm=y\&-geo_id=05000 US06019\&-qr_name=ACS_2008_3YR_G00_DP3YR5\&-ds_name=\&-_lang=en \&-redoLog=false.

29. Columbia County. (n.d.) Household natural hazards preparedness questionnaire. Retrieved December 27, 2007, from http://www.columbiacountyny.com/documents /natural_hazard_questionnaire.pdf.

30. Long Beach California. (n.d.) Community hazards mitigation and preparedness questionnaire. Retrieved January 10, 2008, from http://www.longbeach.gov/civica/filebank /blobdload.asp?BlobID=4401.

31. Saline County. (n.d.) Household natural hazards preparedness questionnaire. Retrieved December 27, 2007, from http://www.salinecounty.org/Questionnaire.doc.

32. Somerset County. (n.d.) Citizen preparedness questionnaire. Retrieved January 10, 2008, from www.co.somerset.nj.us/hazard/citizensurvey.htm.

33. Hilfinger Messias D, Lacy E. Katrina-related health concerns of Latino survivors and evacuees. J Health Care Poor Underserved. 2007;18:443-64.

34. Carter-Pokras O, Zambrana RE, Mora SE, et al. Emergency preparedness: knowledge and perceptions of Latin American immigrants. J Health Care Poor Underserved. 2007;18:465-81.

35. Muñiz B. In the eye of the storm: how the government and private response to Hurricane Katrina failed Latinos. Washington, DC: National Council of La Raza, 2006 Feb 28. 